From the Montezuma records, the following unusual sky observation reports are taken (1932: C. P. Butler, director).

April 13. Horizon to south very hazy with yellowish-looking dust. Nothing further is noted until-

April 22. Good sky. Very hazy over mountains to east.

April 23. Very heavy layer of yellowish haze over mountains to east, extending up to about $10^{\circ}$.

April 24. Very poor sky. Streaks from horizon to zenith, with whitish glare about sun.

April 25 and 26. Same notes as on April 24.

April 27 through 30. Dust in atmosphere almost totally obscures sun.

On April 30 the pyranometer value at air mass $2 \cdot 0$ was 0.131 calorie - ten times the normal value.

It should be noted that Montezuma is more than eight hundred miles north of the erupting volcanoes.

\section{CARE OF THE WOUNDED}

$\mathrm{T}$ HOSE who had the experience of being transported, after the War of 19I4-18, from, say, the less civilized Iraq of those days to a bed in one of the temporary military hospitals in England considered that they were being handled by an organization which it would be diticult to improve. But we realize, when we read the three articles contributed by a Special Correspondent to the Lancet (253, August 19, 1944; 278, August 26, 1944; 383, September 16, 1944), how much more is now being done for the wounded and the sick. These three articles on the wounded from Normandy must be read; they cannot be summarized. They explain why the casualty-rate among the wounded has been low. The doctor and the medical organization go right forward into the battle; paratroops and tanks have their field ambulances; the soldier knows much more about first-aid and about how to keep himself fit; surgical treatment is given early ; blood transfusions are given much earlier; penicillin is available everywhere; and air transport, described in the second article, has been well organized. When they get to Britain, the wounded pass into the hands of the home hospital services and their network of ancillary organizations, which extend right back to the humblest civilian who goes along, when he is asked to do so, to give a pint of blood. The destinies of that blood have been described in the Press and pictured on the cinema screen. They are symbolic of the whole service. It is to be hoped that, after the War, this organization will be applied to national life in peace as well as in war, and that the soldier will bring back into civil life the knowledge of how to keep fighting fit which the R.A.M.C. has taught him so well that "nothing like it has ever been done either in military or civil life".

For those who are interested in this subject, the article entitled "Military Surgery in Geographical Perspective", by Ian Aird, late Lieut.-Colonel R.A.M.C. (Edinburgh Med. J., 51, 166 ; April 1944) will be of great interest. The author deals with surgical strategy and tactics in Libya and discusses the influence of the physiography, climate, water supply, soil bacteriology, dust and sand storms, populations and communications of Libya on the planning of surgery for the campaign there. Little help was obtained from the history of previous North African campaigns. The rapid movement of the war there demanded mobile, self-contained units, and the caravan- and tent-operating theatres used are shown in photographs. The rest of the article describes the surgical technique employed, the water shortage and evacuation of the wounded by air. It may be compared with many other articles on the treatment of war wounds which have appeared in the medical Press.

Almost as frequent have been articles on the transport of the wounded or of those injured in air raids. Among these there have been numerous descriptions of stretchers designed for rapid transport of injured people and adapted for use for artificial respiration as well. D. G. Duff (Lancet, 798, June 17, 1944; see also the Lancet, 739, June 3, 1944) describes one of these stretchers. Dr. Duff's stretcher is the result of experiments made over six years, experience of climbing accidents being included. Photographs of it illustrate its use. It is comparable in weight and ease of production to the standard army stretcher, and can be used as a breech buoy and for Eve's rocking method of artificial respiration. Runners beneath it enable it to "be its own vehicle" on any slope and on rock, grass, scree, heather, ice and snow; or it can be used for lowering a patient from a window. A wheeled undercarriage is available and a collapsible form of it can be got into a package $4 \mathrm{ft} .6 \mathrm{in}$. $x$ 10 in. $\times 4$ in.

\section{BIOLOGICAL STUDIES IN BRAZIL}

RRAZILIAN biologists and medical men have 3 made, and are making, valuable contributions to knowledge. The wide field which they cover is indicated, not only by their medical journals, but also by the policy of some of their biological periodicals, which publish articles on subjects which, in other countries, would be printed in medical literature. Thus the Revista Brazileira de Biologia (3, No. 4 ; 1943) contains papers on immunology, such as those on protection tests with Felix's antityphoid serum, on oxidation and reduction of complement and on the antibodies to the virus of equine encephalomyelitis ; and others on cryo-epilepsy, on Henry's melano-flocculation reaction and on Wolff's bufferprecipitation test in malaria, Chagas's disease and schistosomiasis. Another paper discusses the action of acetylcholine and of adrenalin on the coronary arteries of the Brazilian macacus monkey, Allouata fuscus. The rest of this issue deals with more specifically biological subjects. Thus there are articles on two Lepidoptera, Automolis and Rhipha; and on the unity or duality of the males of the hymenopterous parasite, Telenomus fariai, in which the author concludes that the two classes of males are morphologically identical, produce the same progeny from the female and always have ten chromosomes, while the female has twenty. Their difference in size depends on the amount of food that is available. Other articles deal with a new trematode species, Catadiscus mirandai, from the large intestine of Hemipipa carvalhoi, with some spiders of Chile, with two new species of Stenolemus (Reduviidæ, Hemiptera) and with the hyoid and laryngeal apparatus of some Microchiroptera. Botanists will be interested in the article on the nomenclature of Capsicodendron Dinisii (syn. C. pimentiera, Canellaceæ). The social importance of scientific investigation is discussed by Dr. Oswaldo Cruz, of the famous Institute which bears his name. 
Another Brazilian biological journal, Zoologia (No. 7. 1943. Boletim 32, Universidade de São Paulo, Brasil), although chiefly biological, contains a paper by Paulo Sawaya on the occurrence of acetylcholine in the cardiac tissues of the marine crab, Callinectes dance, which "is perhaps the commonest swimming crab in Brazil". A large quantity of acetylcholine was found in the cardiac tissue. The technique of attempts to perfuse the heart is described and the effects on the heart of acetylcholine, eserine, atropine, nicotine and adrenalin are described. Extracts of the cardiac tissue of Callinectes dance contained substances which acted like acetylcholine on the hearts of the amphibians Bufo marinus and Siphonops annulatus. The experiments indicated that Siphonops annulatus can be used for testing the action of acetylcholine. Five plates record the kymograph tracings (cardiograms) obtained with the hearts of these three species.

The greater part of this issue is, however, occupied by a paper of 246 pages on the Naididxe of Brazil, by Ernesto Marcus, with a summary in English of ten pages, a bibliography of seven pages and 33 plates. The paper discusses the structure, bionomics and taxonomy of 24 species, all found near the city of São Paulo and in the State of São Paulo. They belong to the genera, Chcetogaster, Nais, Dero, Aulophorus, Pristina and Naidium. Some problems of variability, morphogenesis, regeneration and histology are considered.

In the same volume, Michel P. Sawaya discusses the intrazocecial rings of the Crisiid Bryozoa, and Domingos Valente describes his work on the effect of numbers of individuals on the oxygen consumption of the crab Trichodactylus petropolitanus, which normally lives in darkness under stones and water plants in rivers. The author concludes that the isolated animal uses oxygen at a greater rate than do groups of four crabs; and two crabs used more than four. This group effect is not eliminated by darkness. The effect of visual stimuli on oxygen consumption was studied in crabs placed in relation to their own mirror images in aquaria mirrored on one vertical side. The oxygen consumption of isolated crabs thus placed in contact with their own mirror images was decreased. Mirror image and group effects are thus both positive, but the former were not very marked.

\section{G. LAPAGE.}

\section{SYSTEMATICS OF THE POTATO}

A

THOROUGH understanding of potato taxonomy is a necessary pre-requisite of a large-scale programme of breeding for new types. With this in view the British Empire Potato Collecting Expedition sent out by the Imperial Agricultural Bureaux during 1938-39 made extensive collections in Mexico and South America. The systematic results are now described by Dr. J. G. Hawkes (Imperial Bureau of Plant Breeding and Genetics, Cambridge, pp. 142, June $1944,7 s .6 d$.), who has classified all the material obtained on a basis of morphological; geographical and cytological criteria. Five new cultivated and thirty-one new wild species are described in addition to very many new varieties and forms; but although some, twenty cultivated and one hundred and fifty wild species of potato are now known, it is concluded that, at least so far as the wild species are concerned, the wealth of variation still lies practically untouched, and probably three or four times as many wild species await discovery in the less accessible regions.

The cytological investigation of the collections shows that it is only in Mexico that the whole polyploid series occurs. Here only six diploid species are known, whereas tetraploid, pentaploid and hexaploid types are common. In South America diploid wild species are the rule, and there are no pentaploid or hexaploid wild species and only one pentaploid cultivated species. Among cultivated species in every country tetraploid clones occur much more frequently than diploids, triploids and pentaploids.

As regards the origin and evolution of cultivated potatoes, reasons are advanced for supposing that moderately high-yielding wild potatoes were first taken into cultivation in the Lake Titicaca - Cuzco region of north Bolivia and south Peru. Light is thrown upon the problem as to which types of potato were first cultivated by an analysis of the different kinds of weed and semi-cultivated species. This leads to the conclusion that the tetraploid weed species may be either types that had once been cultivated and have now been replaced by higher-yielding varieties of $S$. andigenum, or amphidiploids which were never cultivated to any great extent. The diploid species, on the other hand, are probably the wild species most closely related to our cultivated diploids from which the tetraploids arose before or after their being taken into cultivation. The two tetraploids $S$. andigenum and S. tuberosum (s.str.) are considered to have had a common origin in the south Peru - north Bolivia region and not to have been derived from distinct wild species, while the evidence as to the origin of the European potato is thought to favour an introduction from the Andes, and most probably Columbia, rather than Chile as has been supposed.

\section{STRUCTURE OF THE WALLS OF PHLOEM FIBRES}

$\mathrm{R}$ . D. PRESTON (Chronica Botanica, 7, $414 ; 1943$ ) points out that there is now considerable scope for the botanist, and especially the biophysicist, to make his contribution to the knowledge of the fine structure of the cellulose walls of plant cells.

Owing to their commercial value, the fibres of the phloem (sclerenchyma) have so far been chiefly studied; in these the. X-ray diagram indicates the presence of cellulose chains in the longitudinal direction only, while observations on swollen walls by optical methods have led to the view that at least two layers are present and that they differ in direction of the cellulose chains. Crossed cellulose chains definitely occur in the walls of certain algæ. The X-ray diagrams of hemp and jute fibres reveal the presence of only one direction of cellulose chains which runs parallel with the major extinction plane and remains unaltered during thickening processes of the fibre walls.

However, by optical examination of swollen walls, there is indication of heterogeneity in cross-section which does not appear to be accounted for in entirety by the differential distribution of lignin and pectin. The latter causes also differential swelling of the wall in different regions and leads to the production of striations of various kinds; also the swollen material is easily broken into separate fibrils with associated change in direction of cellulose chains, which appears to have misled at least one worker. Swelling under 